\title{
Editorial
}

\section{Lessons Learned from Synovial Tissue Analysis}

\author{
Paul P. Tak ${ }^{*}, \S$
}

\author{
Division of Clinical Immunology \& Rheumatology, F4-105, Academic Medical Center, University of Amsterdam, \\ Meibergdreef 9, 1105 AZ Amsterdam, The Netherlands
}

Because many inflammatory arthropathies primarily involve the synovial tissue, there has been increased interest in investigations of the pathologic changes in synovial biopsy specimens during the last 2 decades (Reviewed in [1]). This development has been stimulated by technical advances such as the advent of new methods to obtain synovial tissue specimens from actively inflamed joints and clinically quiescent joints under local anesthesia, such as mini-arthroscopy and ultrasound-guided synovial biopsy, and because of the development of new laboratory techniques used to analyse the synovial tissue samples. Systematic analysis of synovial tissue has lead to the identification of key therapeutic targets, such as TNF and IL6 as well as many others that are currently being tested.

Previous work has also shown that there is a relationship between the characteristics of rheumatoid synovial tissue and arthritis activity. The importance of evaluation of synovial tissue samples after experimental treatment has been underscored by the observation that clinical signs and symptoms of arthritis are associated with histological signs of synovitis after treatment of rheumatoid arthritis patients with the monoclonal antibody alemtuzumab, despite profound depletion of circulating lymphocytes. Similarly, rituximab treatment leads to a rapid and significant decrease in synovial B cell numbers in only a subset of rheumatoid arthritis patients, whereas circulating B cells are completely depleted in nearly all patients. Collectively, there is now consistent evidence indicating that analyses of serial biopsy samples can be used as a screening method to test new drug candidates with high sensitivity to change. The absence of changes after treatment would suggest that the therapy is probably not effective, even when only relatively small numbers of subjects have been tested. In contrast, the demonstration of biologic changes in the synovium could provide the rationale for larger, placebo-controlled trials. Most of the synovial biopsy studies have been performed in rheumatoid arthritis patients, but the same approach could be used for the evaluation of novel therapies in patients with

\footnotetext{
*Address correspondence to this author at the Division of Clinical Immunology \& Rheumatology, F4-105, Academic Medical Center, University of Amsterdam, Meibergdreef 9, 1105 AZ Amsterdam, The Netherlands; Tel: +31 20566 7765; Fax: +31 20691 9658;

E-mail: P.P.Tak@amc.uva.nl

${ }^{\S}$ Guest Editor
}

ankylosing spondylitis, psoriatic arthritis and other forms of spondyloarthritis.

The aim of this Special Issue of the Open Rheumatology Journal is to provide a state of the art overview of the features of the synovium in healthy individuals as well as patients with rheumatoid arthritis or different forms of spondyloarthritis. In addition, the authors, who are leading investigators in this field, describe what is known about the synovial tissue response to treatment.

In the first Chapter, Dr. Smith describes the normal synovium, which refers to the soft tissue lining the spaces of diarthrodial joints, tendon sheaths and bursae. It includes the continuous surface layer of cells (intimal lining layer) and the underlying tissue (synovial sublining). The intimal lining layer consists of macrophages and fibroblast-like synoviocytes while the synovial sublining includes blood and lymphatic vessels, a cellular content of both resident fibroblasts and infiltrating cells in a collagenous extracellular matrix. Together, this structure provides a non-adherent surface between tissue elements. Drs. Hitchon and ElGabalawy describe in the second Chapter the changes in rheumatoid synovial tissue, which is characterized by increased vascularity as well intimal lining layer hyperplasia and accumulation of macrophages, plasma cells, T cells, B cells, dendritic cells, natural killer cells, mast cells and neutrophils in the synovial sublining, among other changes. The study of serial synovial biopsies, in the context of proofof-principle trials, successfully distinguished between effective and ineffective treatments in patients with rheumatoid arthritis (Sousa et al., Chapter 3). Decreased disease activity after effective treatment has consistently been associated with a reduction of the number of synovial sublining macrophages across different therapies. This attractive approach can be used during early drug development for screening proposes, supporting which new treatments have higher probability to be beneficial in a large scale clinical trial.

Drs. Appels and Braun emphasize in Chapter 4 the importance of the entheses as a site primarily involved in the peripheral and axial inflammation found in patients with spondyloarthritides and describe the features of the synovium in these conditions. The group of spondyloarthritides comprise ankylosing spondylitis, psoriatic arthritis, reactive arthritis, arthritis associated with chronic inflammatory bowel disease and undifferentiated spondyloarthritis. Next, Chapter 5 describes the synovial 
tissue response to treatment of patients with peripheral spondyloarthritis (Paramarta et al.). Although data are mainly confined to the effects of TNF inhibition, initial studies suggest that the study of serial synovial biopsies could also be used in spondyloarthritis to distinguish between effective and ineffective treatments. Most studies using serial biopsy in spondyloarthritis have been conducted in psoriatic arthritis, which is discussed in more detail by Drs. Codullo and McInnes in Chapter 6. In this condition, serial skin biopsy can be evaluated as well.

Collectively, analysis of molecular markers in synovial tissue is increasingly used to provide insight into the pathogenesis and to provide proof of mechanism during early drug development. Tissue specificity is not a problem, and examination of serial biopsy samples may be used to monitor the response in individual patients and screen for interesting biologic effects at the site of inflammation. It can be anticipated that future development will include the use of more extensive markers of synovial inflammation and joint degradation and the use of panels of biomarkers in synovial tissue samples.

\section{REFERENCE}

[1] de Groot J, Zuurmond AM, Tak PP. Biological markers. In: Firestein GS, Budd RC, Harris ED, McInnes IB, Ruddy S, Sergent JS, Eds. Kelley's Textbook of Rheumatology. $9^{\text {th }}$ ed. Philadelphia: W.B. Saunders Co 2012 (in press).

(C) Paul P. Tak; Licensee Bentham Open.

This is an open access article licensed under the terms of the Creative Commons Attribution Non-Commercial License (http://creativecommons.org/licenses/by-nc/ 3.0/) which permits unrestricted, non-commercial use, distribution and reproduction in any medium, provided the work is properly cited. 